\title{
Socio Economic Impact of Assembly Line Balancing in Garment Manufacturing with the Help of Work Aids
}

\author{
Kamaljit Singh Rana ${ }^{1}$, Dr Jagjit Singh Randhawa ${ }^{2}$, Dr. Parveen Kalra ${ }^{3}$ \\ Article History: Received:11 January 2021; Accepted: 27 February 2021; Published online: 5 April 2021
}

\begin{abstract}
The experimental efficacy of a work station that is ergonomically designed owes its overall reliance on production engineering, especially considering assembly line balancing besides the sustained work output of the assembly line and its snags caused in the production process have been acknowledged since long. The manifestation of these irregularities and consequent inadequacies on persistent shoulder - neck exposure have been studied for this paper with the help of work aids. A conducive workplace based on better ergonomic work station design, influences stress decreased due to the undue strain of repeated actions in an assembly line situation. This makes for resultant assembly line need to get balanced and subsequent to the production most irregularities decrease. It also results in the perpetuation of idle time across the assembly line outputs as compared to when no work aids have been introduced.
\end{abstract}

\section{Focus}

The researcher contribution of this paper is the experimentation conducted on a work table designed for the finishing line segment of the garment manufacturing assembly line. The folding table, as it has been called has flexibility of adjustment of work angle and some advantages over the conventional fixed surface tables.

\section{Method}

Designing aspect apart this Table has been experimented with for usage and stability in the garment manufacturing assembling at three different units. The pilot results have been examined in the light of work done by earlier scholars.

\section{Scope}

The musculoskeletal strain experienced by workers in the garment manufacturing units impacts directly on their work output resulting long term physical and socio-economic implications that tend to effect work output efficiency in the long run.

\section{Results and Findings}

Decreased stress levels show indications of positive usage of this work aid. However, testing is still going on to confirm the preliminary results

Keywords: work aids, ergonomics, musculoskeletal disorders, assembly line, efficiency, production

\section{Introduction}

Sustained maintenance of poor postures pertaining to the neck, trunk and upper extremities during of musculoskeletal aberration and numerous movements that are highly repetitive have consequently resulted in reports of mild to severe pervasiveness grievances affecting the neck, back and upper limbs in the garment manufacturing assembly line. Operators "(Keyserling et al, 1982; Vihma et al, 1982; Punnett et al, 1985; Kumar, 1989; Blader et al, 1991; Vezina et al, 1992; Westgaard and Jansen, 1992). Keyserling et al (1982)". Several studies have found workers in the garment industry suffering persistent musculoskeletal pain in several and singular parts of the body. A frequent location of the pain has been reported to be in the hand while the other musculoskeletal problems have mostly been taken to be occupational hazards pain in neck or back has been reported frequently by garment manufacturing factory workers but the larger proportion of the reports has been studied by several workers to be in the neck, upper back or shoulders. While there have been significant proportion of reports on studies conducted by various scholars during the 1990s to

\footnotetext{
1 "Kamaljit Singh Rana, Department of Production and Industrial Engineering, Punjab Engineering College, (Deemed to be University) Formerly Punjab Engineering College, Chandigarh (U.T.) India."

2 "Dr. Jagjit Singh Randhawa, Department of Production and Industrial Engineering, Punjab Engineering College, (Deemed to be University) Formerly Punjab Engineering College, Chandigarh (U.T.) India."

3." Dr. Praveen Kalra, Department of Production and Industrial Engineering, Punjab Engineering College, (Deemed to be University) Formerly Punjab Engineering College, Chandigarh (U.T.) India."
} 
2000 decade when garment manufacturing was stepped up by the design and fashion industry for the production of mass produced readymade garments. Pain in the hip, knee, leg and foot have also made into the list of physical pain centers for humans working long hours in repetitive tasks.

An incisive review of the available literature has shown that prolonged sedentary work in itself creates troubles with neck and back disorders ultimately resulting in significant and absenteeism medical costs for the organization and the individual (Duquette et al, 1992). It has been observed to pose a problem of large proportions more so as a fairly large number of workers are not doing repetitive sedentary work which entails their having to bend forward putting the trunk and head at an unnatural angle for ensuring better work output. They strain the neck and shoulder muscles much more than they are supposed to be.

It was essential to understand better the actual motivation for the workers to adopt their postures in that particular manner. The first objective was to recognize the necessary factors affecting the postures adopted by assembly line workers at the garment manufacturing the workplaces. The second objective was to design under some practical guidelines for the work aids so that the operations of the garment manufacturing assembly line could be carried out in a seated position. The task of sorting, folding and ironing as well as packing garments required the simultaneous use of both hands in coordinated movements through several repetitive gestures. It can result in awkward postures of extreme joint exercise that usually arise picking up and folding garments then pushing them forward with the opposite hand manipulating the materials while spontaneously keeping them in position for folding and performing various movements with the right hand. This work has been observed to be maintained throughout the individuals work shift. There is relaxation or change perhaps for some new, ancillary tasks, which tend to create an occasional change in the regular work position.

Stress at work has been correlated with subjective complaints from various points on the upper half of the body. Such targeted complaints have concentrated on the legs and feet most frequently other commonly heard complaints were for neck and shoulders besides the back. These were subjective complaints from the neck, shoulders and legs including feet were compounded into work dissatisfaction. This aspect has not been correlated with any physical signs, but has direct or indirect impact on station-bound work. The work aid designed as a folding table is hoped to give better work output as compared to the conventionally used workstations commonly observed on an assembly line.

During folding of the garments the frequent arm movements are more frequent. These repetitive movements results in the trapezius and infraspinatus muscle activation levels. Observation of these movements over time suggested that mechanical exposure of assembly workers in conducting such tasks can result in counteracting effect on overall physical fatigue. Thus, improved ergonomic design contributed by work aids through effective production engineering can help ameliorate the work output.

A study of the available literature on the subject brought to light the fact that after the nineties when focus on musculoskeletal aberrations that were work related came into focus, there was a period of lull as scholars concentrated on other subjects. Some of the early works are discussed in the given literature review.

\section{Review of Literature}

The concept of ALB or Assembly Line Balancing that has been studied and discussed as a problem featuring in various industries (Becke \& Scholl, 2006; Erel \& Sarin, 1998, Hoffmann, 1992; Pinto, Dannenbring \& Khumawala, 1983).

In the garment manufacturing industry, sewing machine operators and others in the assembly line are "known to experience considerable musculoskeletal distress due to static postures that have been maintained during the entire working period, as also those due to the highly repetitive manual tasks performed" (Vihima et al., 1982; Punnett et al, 1985). The folding operation is illustrated by working through shoulder, arm, hand movements in a sitting posture with the trunk flexed forwards and operator's head.

While conducting a study on garment manufacturing industry assembly line workers Keyserling et al (1982) analyzed the working at two work processes. Firstly, the examined workers while working on tasks of concentration like when they tended to guide any part of the garment, say a blazer through certain maneoveres where both handsmoved parallel to a section of the sagittal aspect. When doing this they did not flex the shoulders. In fact they were spending over 70 percent of their time in a position, where the back was continually bent. During their work on an even more care 
requiring part of the task the workers tended to lift up the elbows also flexed the shoulders. However, they tended to bend their necks forward to promote better concentration. The flexion of the neck muscles for long durations coupled with a degree of back muscle flexion was observed to be common in the most complex of tasks in the garment manufacturing assembly line balanced situation in any such unit.

Keyserling et al (1982) recommended the inclusion of the "sewing table in a manner similar to a drafting table". This was expected to reduce the tendency of the operator to lean forwards. Another of their suggestions was reducing the friction between the work surface and the fabric being worked upon. It was observed that the total effort was on "pushing the fabric through the machine and the entire load rested on the hands and wrists". Haslegrave and Gregg (1988) observed "the effects of work on physical posture and made detailed recommendations for changes needed in layout of the sewing table".

Delleman and Dul (1989) examined the "design parameters for sewing table height" which impacted relatively on elbow height were a function of the table slope as well. Depending upon the "measurements of the operators" head/trunk postures and left upper arm elevation as well as postural discomfort scores", the authors "recommended that table height should be adjusted to about $5 \mathrm{~cm}$ above elbow height, and the table surface" was advised to be inclined at about $10^{\circ}$ towards the operator. This was considered to be significantly influencing the head and trunk as also the upper arm postures.

Thus, a review of various studies concentrated on the layout of garment manufacturing unit workstations suggested the desirability of an inclined table. These results highlighted the need for an assembly line conducive table with these improvements to accommodate, who could operate adopt postures that were less strenuous for their head and neck movements. They did not have to bend their upper bodies to an undesirable extent.

Various scholars concluded that, "the sewing machine operators use hands to handle, control, or feel objects, and tools; sit for long periods of time, and repeat the same motions" (Kaergaard and Andersen, 2000; Wang et al., 2007). "For this reason, a high prevalence of musculoskeletal symptoms of neck, shoulder, back, hand/fingers and lower extremities have been found in studies of female SMOs" (Kaergaard and Andersen, 2000; Brisson et al., 1989; Kilroy and Dockrell, 2000; Vihma, 1982).

Comparatively, there have been very few approaches on studying "the effect of etiological mechanisms on causing" Musculo Skeletal Disorders (MSDs) which is even today not fully understood, there have been several studied that have provided evidence that "environmental factors and personal factors have an effect on the occurrence of MSDs".

\section{Research Objectives}

Reports from several earlier researchers have documented that "the root cause of musculoskeletal discomfort among the seated workers are due to the awkward constrained work posture, monotonous and repetitive tasks" (Corlett, 1981; Bhatnager et a., 1985; Vihma et al., 1982). The prevalence of musculoskeletal complaints affecting different body region is high among sewing machine operators" (Vihma et al., 1982, Keyserling et al., 1982; Punnett et a., 1985; Westgaard and Jansen, 1992).

It has been observed and concluded by most workers in the field that "stressful awkward postures adopted for work shift or more than work shift would be regarded as health hazards" (Brider, 2003). The users of "ergonomically designed workstations are likely to benefit in terms of task performance, as well as in terms of less discomfort/fatigue, sick levae, and disability caused by musculoskeletal load" (Delleman 1999 and Delleman and Dul, 2002).

The objective promoting the current research work was to study and attempt to record re risk factors that are ergonomically dependant on the working individual's posture, inherent stress and the tolerance level for repetitive tasks. The study was conducted using simple observational mechanisms, across a range of jobs in different garment manufacturing industries the objective was also to measure the outcome defined through self-reported musculoskeletal pain experienced in static position or working position through three working cycles of the workers. An attempt was made to ascertain a possible existence of the relation between the tediousness of the task at hand and the tolerance level of the worker as also their complaints that bordered directly on MSD's occurrence. 


\section{Methodology}

A pilot study had been undertaken to explore the feasibility of an inclined Table.

(i) The maximum part wherein the work expanse of the assembly line worker could be benefitted.

(ii) Make an effort to record effect of task on the worker

(iii) The relationship between postures of the arm and the trunk as also the positioning of the head while folding and finishing stages in the assembly line process under different workstation.

Once a table had been designed as a work aid there was the task of taking requisite observations and measurements of the workers postures when they were working at the redesigned table under various conditions of table inclination as also the workers seated and standing position.

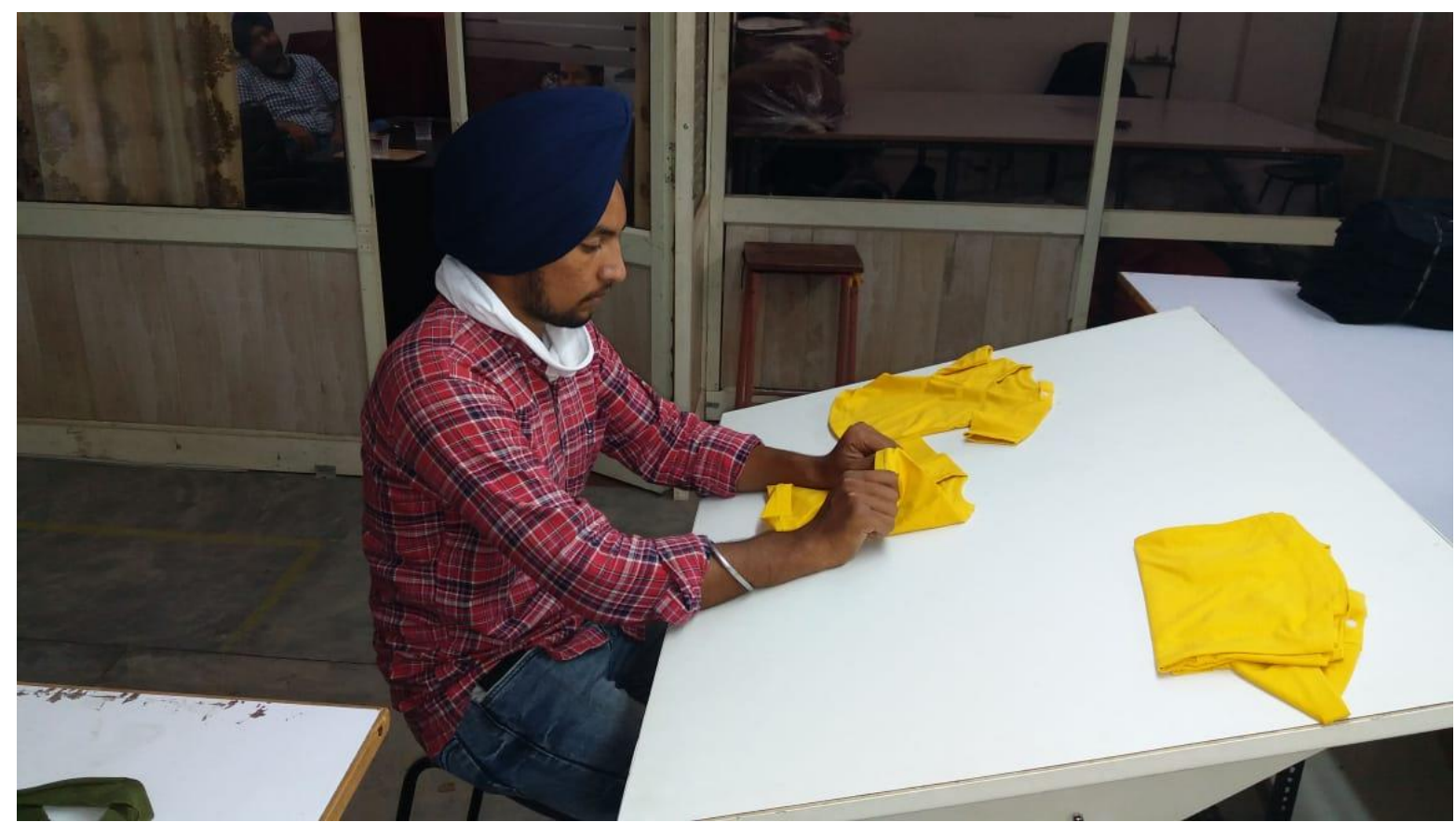

Picture 1: Elbow, arm, wrist (relaxation observed at 30 degrees slope angle of the Prototype Table for Folding at finishing stage of garment manufacturing assembly line

\section{Data Findings and Discussion}

The study findings have given insights into the way in which an assembly line operator's posture has been influenced by the movements, height and angles of work. The configuration of the table requires optimum performance levels, which require being tested over repeated movements

The results confirmed that there was marked advantage that could be gained by the worker and the entire garment manufacturing unit's overall production. It was the adjustable slope of the prototype or the folding finishing stage table. This experiment showed that the postures adopted in accordance with the preferred slope of table at various degrees during the experimental conditions evidently reported by workers at the finishing stage of assembly line showed that the configuration of the table at a slope of $30^{\circ}$ was found to be most acceptable. 


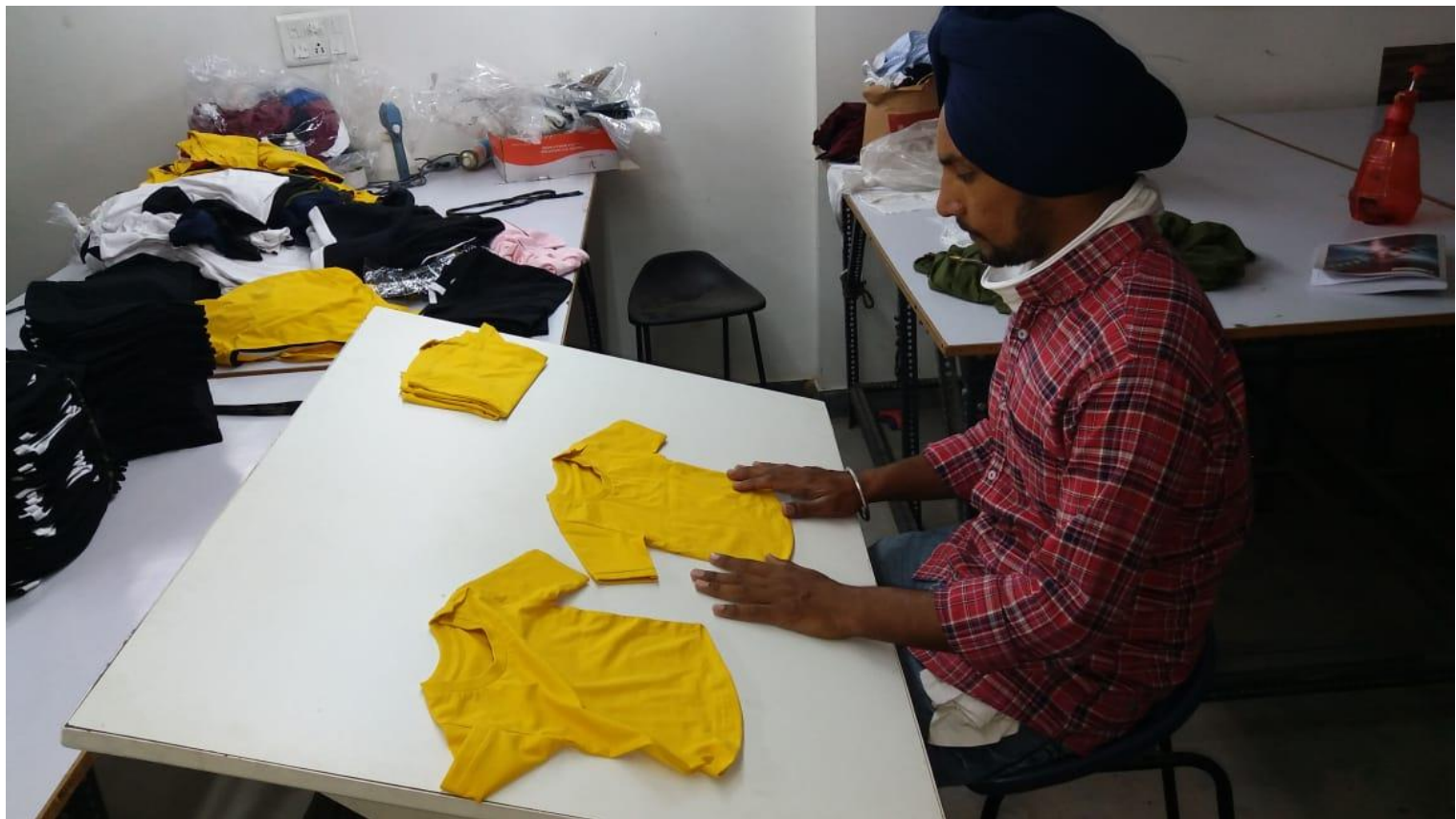

Picture 2: Shoulders, trunk tension observed to be eased in the worker seated at 30 degrees inclined Prototype table for folding. The seated posture of the worker was video graphed through three work cycles. Personal comments of the workers reported "better comfort level" through the task as compared to earlier tables".

The modifications proved to be feasible and there was no evidence found to record any form of deterioration in quality of work being done during the folding of the garments at the finishing stage.

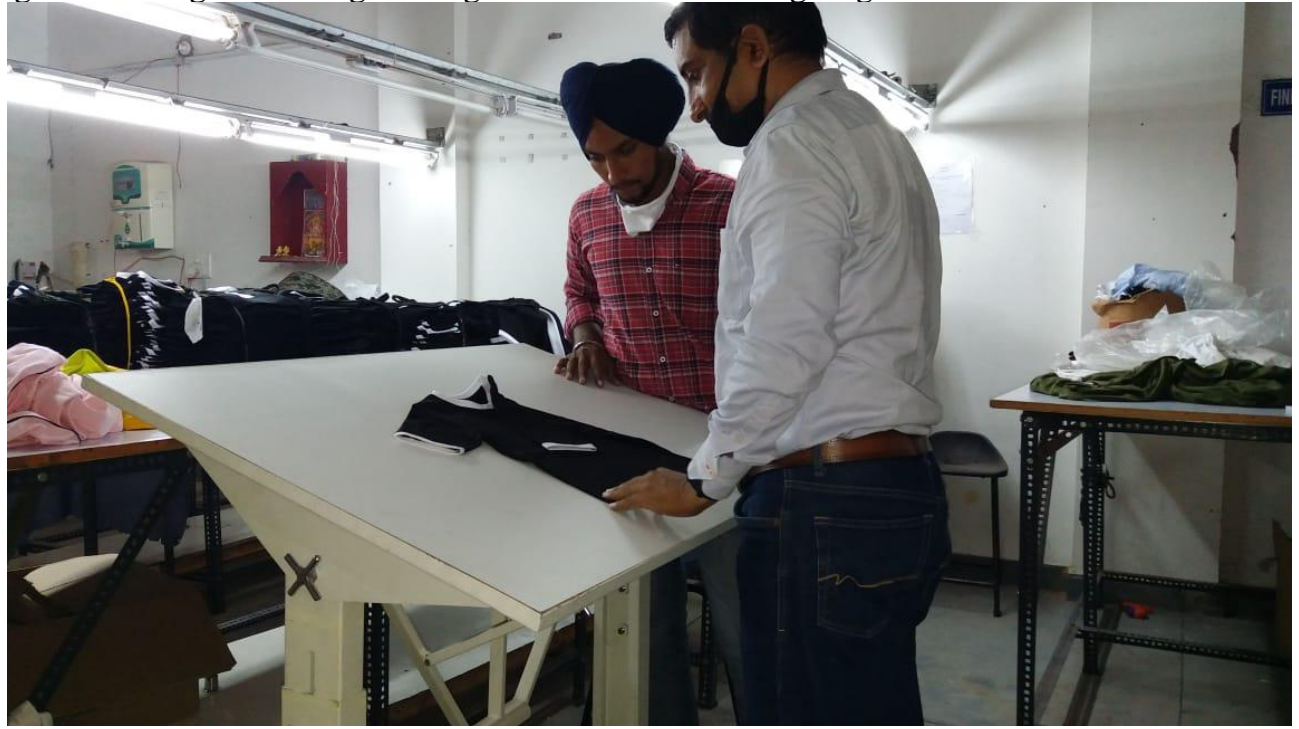

Picture 3: Demonstrating Finishing stage of Garment Folding using Prototype of table. The slope of the table has been adjusted to 30 degree angle. Here hand movements are smooth as ease of operation with both hands is possible. There is smooth movement with least stress and tension of arm, wrist and hand muscles.

(i) Effect of Working on an Inclined Flat Surface

Several researchers have investigated the efficacy of "sloping work surfaces for assembly tasks in the electronics industry" (Westgaard and Aaras, 1985; Rohmert and Mainzer, 1986; Schuldt et al, 1986). They "measured the level of neck and shoulder muscle activity in simulated tasks and found that muscle activity had been reduced when the workers adopted a more upright posture while using an inclined table". The studies, therefore, "suggest that sloping 
work surfaces can be useful in improving posture during some of the assembly line specific work tasks" in various sections of the garment manufacturing industry.

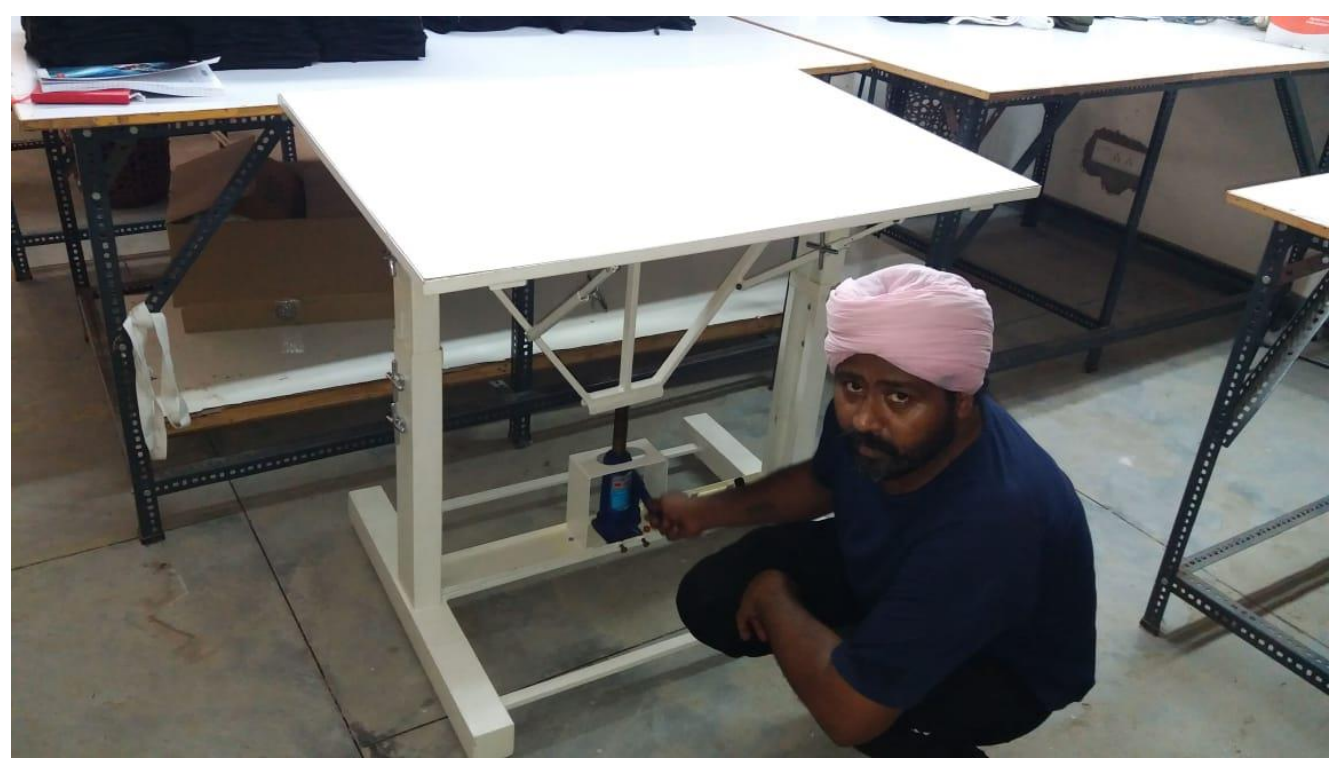

Picture 4: Technical management of table height and slope through adjustment controls that can be set to comfort level of the worker. The slope operations are flexible from 0 to 45 degree.

\section{Recording Posture for Conducting Analysis}

The researcher used three simultaneously recording camera's for capturing the postures of workers while he or she went through the everyday work of folding the clothes. The cameras were focused on providing views that would enable an analysis to be attempted of the head, neck and trunk as well as shoulder flexion, besides repeat actions of both right and left arms.

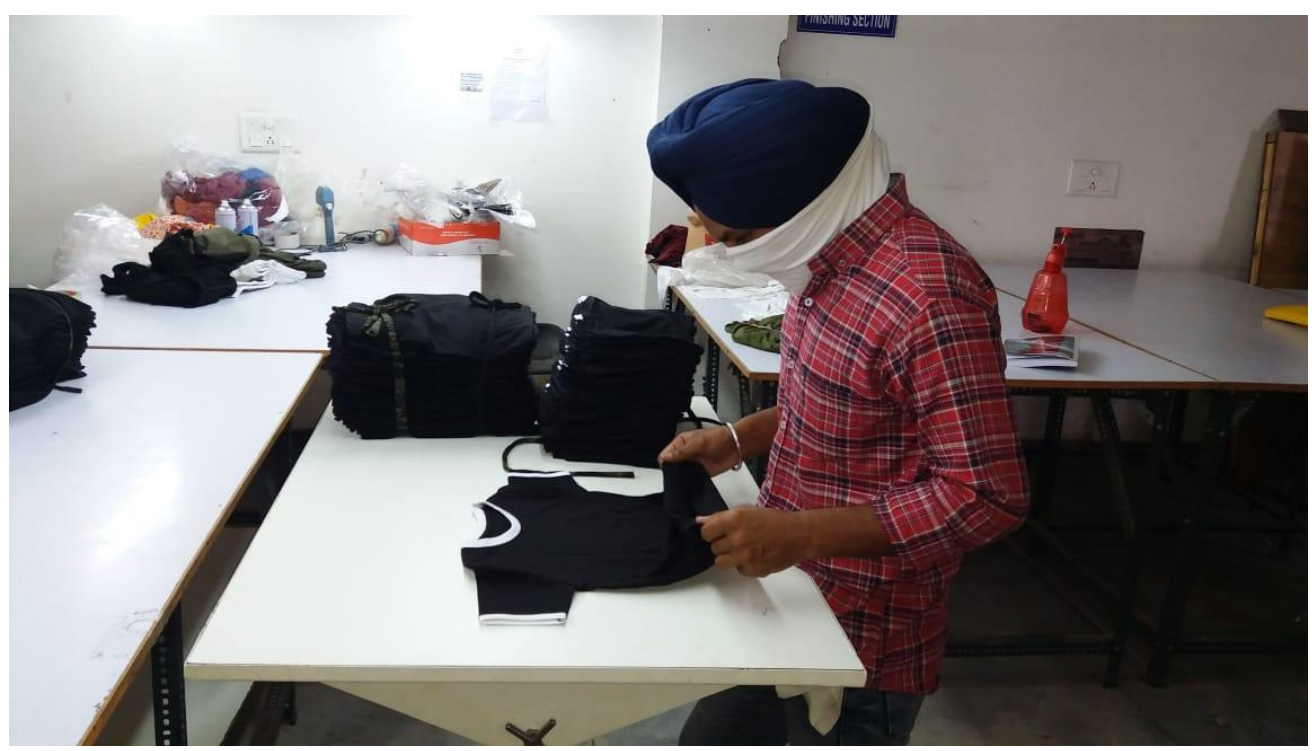

Picture 5: Comparison of Efficiency Increase with Prototype table for folding at flat position (0 degrees) and the muscular tension noted 

Aids

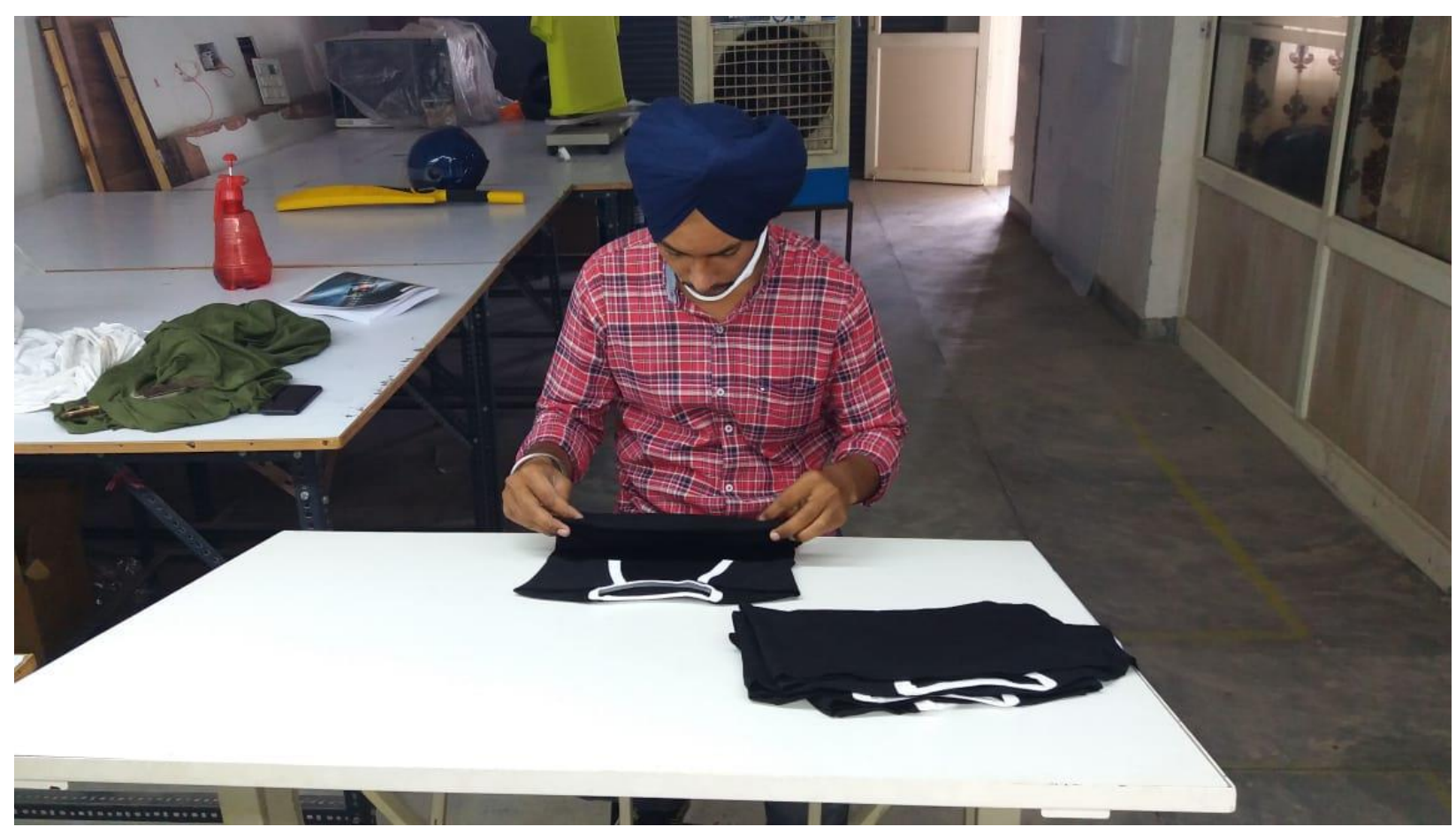

Picture 6: Prototype table inclined at 30 degree improved efficiency as workers could sit and and there was lesser tension observed in the shoulders and arms. When times through three work cycles the efficiency of folding garments of the same worker was seen to increase by 22 per cent (based on number of garments folded I the same time at $0^{\circ}$ and $30^{\circ}$ angles)

Table 2: The Functions Performed

\begin{tabular}{|l|l|l|}
\hline Sr. No. & Objection Function Variable Dependant & Difference \\
\hline 1 & $\begin{array}{l}\text { Posture (Variable) } \\
\text { a. Angle of Trunk } \\
\text { b. Angle of Neck } \\
\text { c. Angle of Arm }\end{array}$ & $\begin{array}{l}\text { Should be bigger } \\
\text { should be bigger } \\
\text { should be Smaller }\end{array}$ \\
\hline 2 & $\begin{array}{l}\text { Posture (Perceived) } \\
\text { a. Angle of Trunk } \\
\text { b. Angle of Neck } \\
\text { c. Angle of Arm }\end{array}$ & $\begin{array}{l}\text { Should be bigger } \\
\text { Should be bigger } \\
\text { Should be bigger }\end{array}$ \\
\hline 3 & $\begin{array}{l}\text { Discomfort Causes in Posture } \\
\text { Head, Trunk, Neck, Shoulder, Arm, Discomfort due to }\end{array}$ & Smaller the better \\
\hline 4 & Endurance Time & Larger the better \\
\hline 5 & Overall workstation Adjustment & Smaller the better \\
\hline
\end{tabular}

Fig 1: Perceived Positioning to Postural Correction for Assembly Line Balancing 


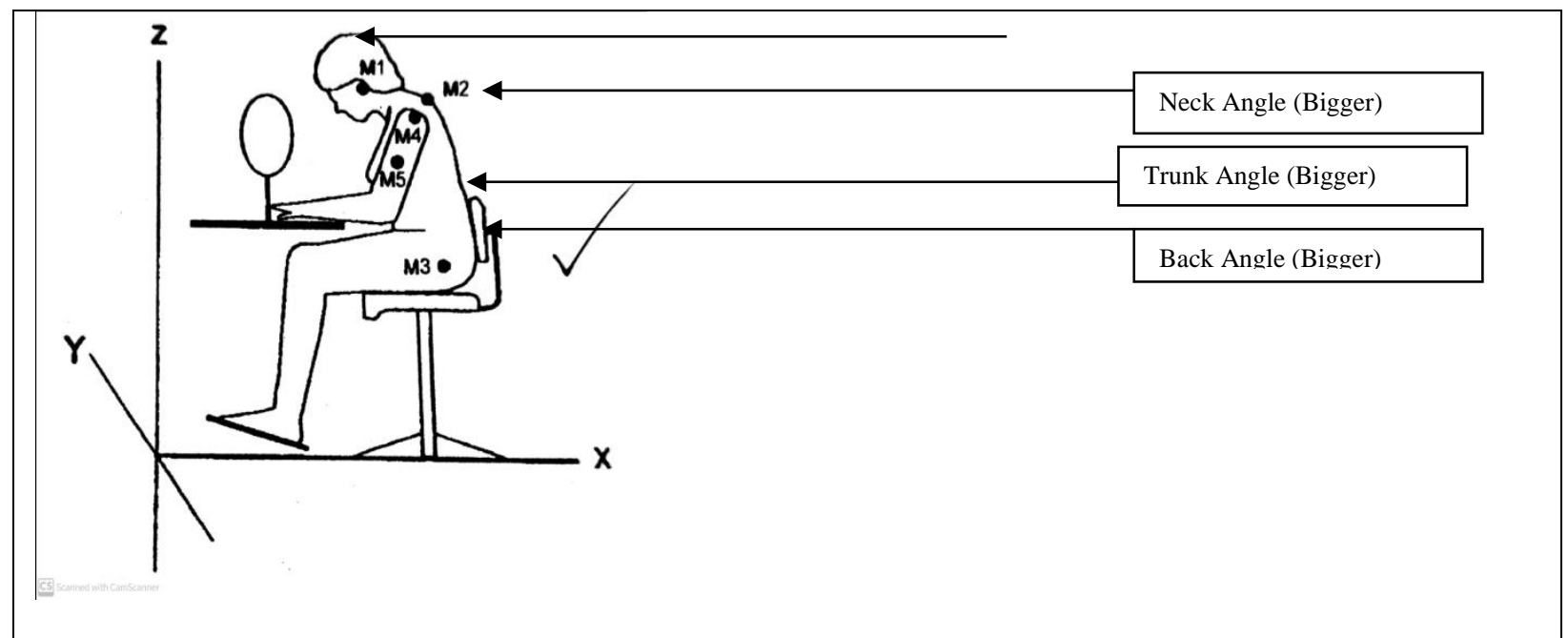

Source: Compiled by Researcher

Fig. 1 The Normal Posture of the Assembly Line Worker stresses Several Muscles. (Head, Neck, Shoulder, Trunk and Back as well as Elbow, arm and wrist pain are common complaints among workers either short term or long terms.

For purposes of analysis some dependent variables as well as posture variables were identified. All observations were based on them

The Angle of the Trunk (TA): This is measured as juxtaposed against an imaginary ' $\mathrm{X}$ ' and ' $\mathrm{Y}$ ' axis. The ' $\mathrm{Y}$ ' axis is he vertical line held parallel to the seated or standing worker and the ' $\mathrm{X}$ ' axis is the horizontal line parallel to the surface on which the worker in seated or standing. The angle is measured when position of Trunk is compared against the ' $\mathrm{Y}$ ' axis.

Angle of the Neck (NA): This is the angle comparable to both the ' $\mathrm{X}$ ' and ' $\mathrm{Y}$ ' axis.

Angle of the Shoulder (SA), This is measured when a comparison is made between the imaginary straight line is drawn between shoulders and the horizontal surface (Delleman and Dul, 2002).

The Measurements were thus Focused on:

1) Flexion and Extension of the trunk has been taken to be the angle between an imaginary line that is seen to be passing across the shoulder and hip joints and the vertical ' $\mathrm{Y}$ ' axis. This also records he head and neck flexion.

2) The shoulder joint flexion was recorded keeping the shoulder and hip joint focus on the sagittal plane. It was a record of the upper arm flexion.

3) Shoulder-Elbow-Hand Movement

4) Measuring the comparatives of the vertical and horizontal lines as presented by the length and breadth of the human body the worker on the assembly line went through various motions which were recorded on camera to promote measurement of the movements. These were done the basis of video recordings.

The time spent by the workers while holding themselves across a wide range of repetitive movements through three work cycles. Care was taken to ensure that the prolonged impact of the particular posture. The percentage of repeated work cycles through similar motions of particular body got calculated simultaneously and separately from the video recordings that had been conducted. The posture observations were averaged from three work cycles on the works focusing especially on the posture specifics of individual workers on a particular task. 


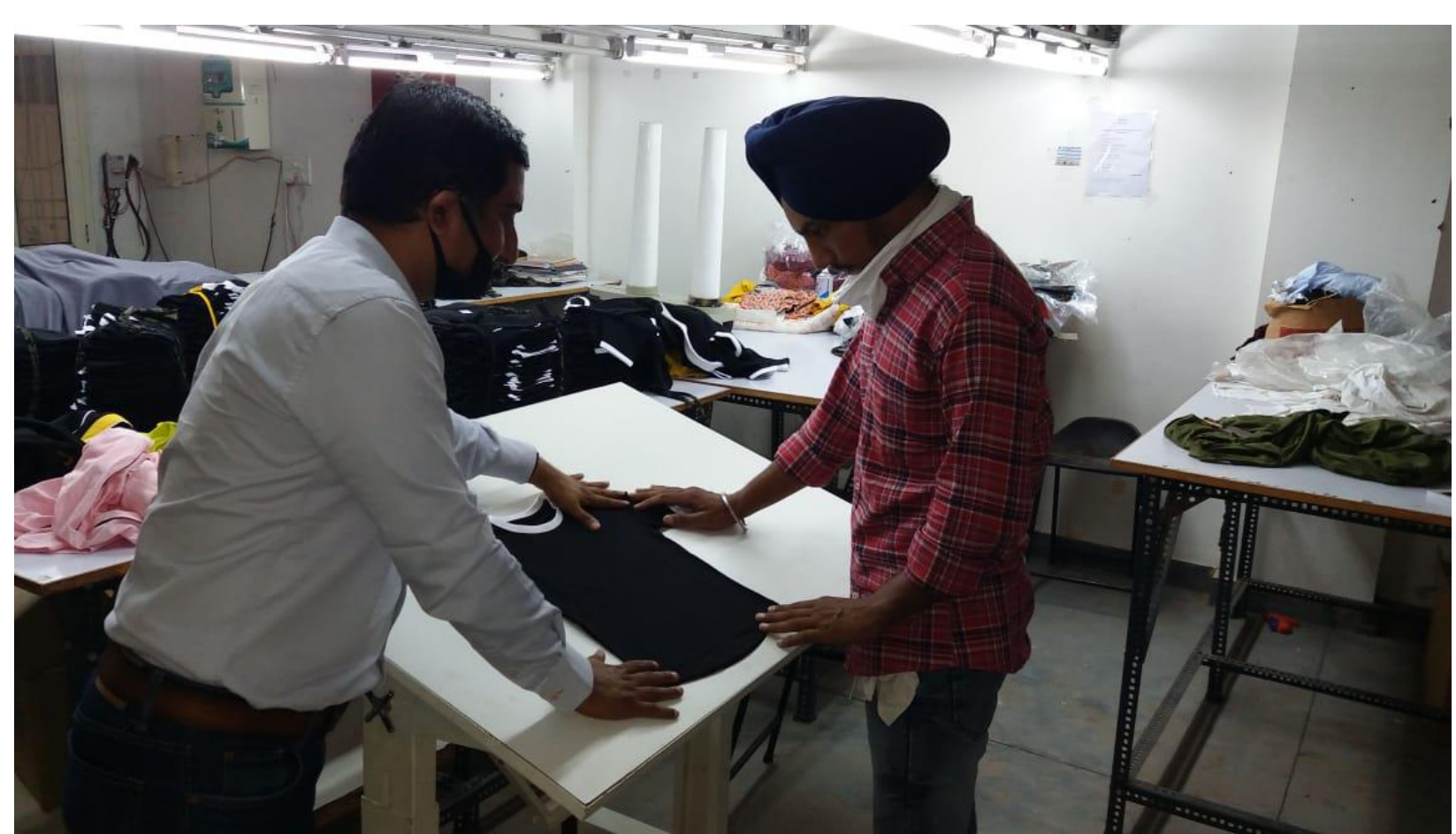

Picture 7: Demonstrating Finishing Stage Using Prototype of table for folding garments. Table slope at 45 degree angle. Worker facilitated for garment folding while standing up. Shoulder tension negligible as muscles are comparatively relaxed.

An average count conducted over here work cycles indicated the varying position and posture of the worker were taken into consideration during the performance of all movements related to the task of folding garments at the finishing end of the garment manufacturing assembly line.

Table 1: Recording maximum Flexion of Head, Neck, Shoulder, Trunk

\begin{tabular}{|l|l|l|}
\hline $\begin{array}{l}\text { Experimental } \\
\text { Conditions } \\
\text { Shape }\end{array}$ & Maximum flexion of Trunk (in degrees) & Maximum flexion of Head/neck (in degrees) \\
\hline Table Slope & Mean & Mean \\
\hline $0^{0}$ & 18.1 & 36 \\
\hline & 15.9 & 38 \\
\hline $30^{0}$ & 17.6 & 35 \\
\hline & 8.2 & 33 \\
\hline & 7.8 & 32 \\
\hline $45^{0}$ & 9.6 & 34 \\
\hline & 5.1 & 35 \\
\hline & 3.5 & 36 \\
\hline & 4.2 & 32 \\
\hline
\end{tabular}

Source: Field data

\section{Conclusions and Scope for Further Research}

Observations made during the study also showed that the slope of the table significantly influenced the trunk, shoulder and neck as well as arm postures of the workers. A titled table gave the worker the capacity to hold himself or herself in an upright posture. Observations showed that the maximum mean flexion of the trunk and shoulders was decreased 8 to 10 degrees whenever he slope of the table the table slope was raised $30^{\circ}$ or even $45^{\circ}$. This result was in agreement with the studies conducted earlier by Wick and Drury (1985) and Delleman and Dul (1989). 
It must be noted, however, that maximum usefull impact of the slope of the table was seen to be at $30^{\circ}$. It showed maximum effect while it was observed that there was much better output than when the angle had been increased to $45^{\circ}$. Looking at the magnitude of work done during the time cycle it was apparent that the workers could perform significantly better when the garment folding table prototype was at a slope of $30^{0}$ to $45^{0}$ no matter whether they were in a standing or seated position.

In the workers views also the table slope at $30^{\circ}$ was found to be adequate. However, they felt that the $45^{0}$ slope was too steep. They felt this could probably be due to the tendency of lighter material to slip onwards if the slope of the prototype table for folding garments was higher.

Thus, while the results are conclusive there is tremendous scope for further research on the subject as ergonomic work aids are an essential part of industrial productivity.

\section{Reference}

1. Aaras, A., Westgaard, R.H. and Stranden, E. 1988 'Posture angles as an indicator of postural load and muscular injury in occupational work situations' Ergonomics 31 (6), 915-933

2. Bhatnager, V., Drury, C.G. and Schiro, S.G. 1985 'Posture, Postural discomfort, and performance' Hum Factors 27 (2) 189-199

3. Blader, S., Barck-Holst, V., Danielsson, S. Ferhm, E., Kalpamaa, M., Leijon, M., Lindh, M. and Markhede, G. 1991 'Neck and shoulder complaints among sewing-machine operators' Appl Ergonomics 22 (4), 251-257

4. Brider, R.S., 2003. Introduction to Ergonomics, second ed. Talyor and Francis Publication.

5. Chaffin, D.D. 1973 'Localised muscle fatigue - definition and measurement' J Occup Med 15 (4), 364-354

6. Carl Zetterberg et al., (1997), "Neck and upper extremity problems in car assembly workers. A comparison of subjective complaints, work satisfaction, physical examination and gender", International Journal of Industrial Ergonomics 19 (1997) 277-289.

7. Dellman, Dul, 2002, "Sewing machine operation: workstation adjustment, working posture, and workers' perceptions, International Journal of Industrial Ergonomics 30, (2002), 341-353.

8. Dillard and Schwager, 1997, Ergonomic equipment investments: benefits to apparel manufacturers, International Journal of Clothing Science and Technology, Vol. 9 No. 4 1997, pp. 285-300.

9. Eastman, M.C. and Kamon, E. 1976 'Posture and subjective evaluation at flat and slanted desks' Hum factors 15 (1), $15-26$

10. Guangyan Li, Christine M. Haslegrave and E. Nigel Corlett, (1955), "Factors affecting posture for machine sewing tasks- The need for changes in sewing machine design", Applied Ergonomics Vol 26, No.1, pp. 35-46, 1995.

11. Hira, D.S. 1980, 'An ergonomic appraisal of educational desks' Ergonomics 23 (3) 213-221

12. Ma, L., Chablat, D., Bennis, F. Zhang, W., 2009. A new simple dynamic muscle fatigue model and its validation. International Journal of Industrial Ergonomics, 39, 211-220.

13. Ozturk, Esin, 2011, "Investigating of musculoskeletal symptoms and ergonomic risk factors among female sewing machine operators in Turkey", International Journal of Industrial Ergonomics, 41 (2011) 585-591.

14. Schierhout, Myers, Bridger, "Musculoskeletal pain and workplace ergonomic stressors in manufacturing industry in South Africa", International Journal of Industrial Ergonomics, 12 (1993) 3-11.

15. Shuval, K., Konchin, K., 2005. Prevalence of upper limb extremity musculoskeletal symptoms and ergonomic risk factors at a hi-tech company in Israel. International Journal of Industrial Ergonomics, 35, 569-581

16. Song, Wong, Fan and Chan (2006), "A recursive operator allocation for assembly line-balancing optimization problem with the consideration of operator efficiency", Computers \& Industrial Engineering, 51 (2006) 585-608.

17. Shihan Bao et al, (1997), "Interactive effect of ergonomics and production engineering on shoulder-neck exposure- A case study of assembly work in China and Sweden", International Journal of Industrial Ergonomics 20 (1997) 75-85.

18. Tondre, Deshmukh 2019, "Guidelines to sewing machine workstation design for improving working posture of sewing operator," International Journal of Industrial Ergonomics, 71 (2019) 37-46.

19. Wang, P., Rampel, D., Harrison, R., Chan, J., Ritz, B., 2007. Work-organizational and personal factors associated with upper body musculoskeletal disorders among sewing machine operators. Occupational and Environmental Medicine. Doi: 10.1136.oem.2006.029140 www.oem.bmj.com (available 23.05.07)

20. Yun, M., Lee, Y., Eoh, H., Lim, S., 2001. Results of a survey on the awareness and severity assessment on upperlimb work-related musculoskeletal disorders among female bank tellers in Korea. International Journal of Industrial Ergonomics, 27, 347-357. 